\title{
The Adoption of a Virtual Reality-Assisted Training System for Mental Rotation: A Partial Least Squares Structural Equation Modeling Approach
}

Chen-Wei Chang ${ }^{1}$, PhD; Shih-Ching $\mathrm{Yeh}^{2}$, PhD; Mengtong $\mathrm{Li}^{3}, \mathrm{MA}$

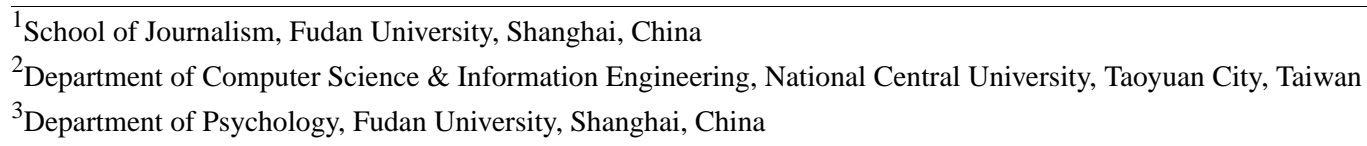

Corresponding Author:

Shih-Ching Yeh, PhD

Department of Computer Science \& Information Engineering

National Central University

No 300, Zhongda Rd, Zhongli District

Taoyuan City, 32001

Taiwan

Phone: 88634227151 ext 35313

Email: shihching.yeh@gmail.com

\section{Abstract}

Background: Virtual reality (VR) technologies have been developed to assist education and training. Although recent research suggested that the application of VR led to effective learning and training outcomes, investigations concerning the acceptance of these VR systems are needed to better urge learners and trainees to be active adopters.

Objective: This study aimed to create a theoretical model to examine how determining factors from relevant theories of technology acceptance can be used to explain the acceptance of a novel VR-assisted mental rotation (MR) training system created by our research team to better understand how to encourage learners to use VR technology to enhance their spatial ability.

Methods: Stereo and interactive MR tasks based on Shepard and Metzler's pencil and paper test for MR ability were created. The participants completed a set of MR tasks using 3D glasses and stereoscopic display and a 6-degree-of-freedom joystick controller. Following task completion, psychometric constructs from theories and previous studies (ie, perceived ease of use, perceived enjoyment, attitude, satisfaction, and behavioral intention to use the system) were used to measure relevant factors influencing behavior intentions.

Results: The statistical technique of partial least squares structural equation modeling was applied to analyze the data. The model explained $47.7 \%$ of the novel, VR-assisted MR training system's adoption intention, which suggests that the model has moderate explanatory power. Direct and indirect effects were also interpreted.

Conclusions: The findings of this study have both theoretical and practical importance not only for MR training but also for other VR-assisted education. The results can extend current theories from the context of information systems to educational and training technology, specifically for the use of VR-assisted systems and devices. The empirical evidence has practical implications for educators, technology developers, and policy makers regarding MR training.

(JMIR Serious Games 2020;8(1):e14548) doi: $\underline{10.2196 / 14548}$

\section{KEYWORDS}

virtual reality; computer simulation; educational technology; training programs

\section{Introduction}

\section{Background}

Research on the acceptance of new information systems and technologies provides empirical evidence guiding decision-making processes in regard to system developments, educational implications, and other practices. For example, in the fields of information systems and behavioral science, robust models (eg, technology acceptance model, TAM; [1]) have been proposed and repeatedly replicated in different contexts to 
examine and better understand the processes of accepting new technologies and systems. In recent years, virtual simulation tools such as the VIVE (HTC Corporation) have been developed and have become more prevalent. These tools create a user experience that better engages cognitive, visual, and motional perceptions. As virtual reality (VR) is different from other information systems - in that users can perceive stereoscopic $3 \mathrm{D}$ objects and it is capable of changing fields-of-view while simultaneously interacting with the content via virtual controllers or motion sensors - this study sees a need to explore users' acceptance of such emergent technology.

Although VR technologies are relatively new and require acceptance research, they have been applied to modern learning and training systems and shown effective outcomes (eg, [2,3]). For instance, a recent study conducted by Yeh et al [2] explored using VR for mental rotation (MR) training. MR is a kind of cognitive ability that uses human spatial imagination to rotate an object in a $2 \mathrm{D}$ or $3 \mathrm{D}$ space $[2,4,5]$. In a stereoscopic and interactive virtual environment, the results of pretest-posttest comparison suggested that the VR training improved learners' MR ability [2]. These results led to this study's interest in gauging the factors that would encourage learners to use the VR system to enhance their spatial ability, as the MR ability influences an individual's learning activities relying on spatial cognitions including those in the field of medical science. Take anatomy learning as an example. Research has shown that MR ability and the outcome of anatomy learning were positively correlated [6,7]. Hoyek et al [7] conducted an experiment comparing 3 groups of anatomy learning: (1) attending anatomy class and receiving MR training (ie, the treatment group), (2) attending anatomy class only (ie, the comparison group), and (3) neither attending anatomy class nor receiving MR training (ie, the control group). The results concluded that the intervention of MR training positively influenced the students' performance in the anatomy test.

Given the developments and research stated above, this study intended to understand the users' complex psychological processes of accepting the VR-assisted MR training system. The empirical results could extend current theories of acceptance from the context of information systems to educational and training technology, specifically for VR-assisted systems and devices. The main goals of this study were, therefore, to (1) create a behavioral model to better understand the adoption of VR technology for MR training, (2) provide suggestions to educators and technology designers regarding the application and improvement of VR training technology for MR, and (3) establish a stepping stone for future researchers and practitioners interested in incorporating VR technology into other educational and training activities for their users.

\section{Theoretical Framework and Research Hypotheses and Question}

To comprehend how an information system is accepted by users, Davis et al [1] proposed the TAM, developed from Fishbein and Ajzen's [8] Theory of Reasoned Action for predicting and understanding an individual's rational behavior and decision making. The TAM model has been frequently used to research the acceptance of a new information and computer system and technology, including those for educational purposes and settings (eg, [9,10]) and has recently been applied to better understand the adoption of VR-assisted training and educational systems (eg, [11,12]). Regarding the design of user interface, TAM assumes that perceived ease of use (PEOU) influences users' attitude (ATT) toward an information system and that ATT affects their behavioral intention to use (BIU) it. This study hypothesized that the same effects apply to our VR-assisted MR training system.

\section{H1: Users' PEOU of the MR system predicts their positive ATT toward it.}

\section{H2: Users' positive ATT toward the system predicts their BIU.}

As technology has developed, the TAM model has progressed and evolved. Davis et al [13] found that both extrinsic (eg, perceived usefulness [PU] and PEOU) and intrinsic (eg, cognitive enjoyment) motivations affected users' behavioral intention and actual use of an information system. Extrinsic motivations are involved with the rewards via actual use, such as the enhancement of job efficiency and increase of salary. On the other hand, intrinsic motivations emphasize the rewards in the experience as the ultimate goal, such as the enjoyment of an activity. By empirically testing the relationships of intrinsic and extrinsic motivations, Davies found that PU and perceived enjoyment (PE) were affected by PEOU. Hence, we postulated $\mathrm{H} 3$ for the use of our system.

\section{H3: Users' PEOU affects their PE when using the $M R$ training system.}

Except for the PU and PEOU as the 2 determinants, researchers started to explore an individual's enjoyable experiences after Davis et al [13]. PE has been verified to have effects on ATT and satisfaction (SAT) with information systems and technology. For example, PE influenced users' positive ATT and intention to use the World Wide Web [14]. In digital learning, trainees' cognitive playfulness affected their learning outcomes, positive mood, and SAT with the training system [15]. On the basis of this evidence, we proposed $\mathrm{H} 4$ and $\mathrm{H} 5$.

\section{H4: Users' PE predicts their positive ATT toward the $M R$ training system. \\ H5: Users' $P E$ predicts their SAT with the MR training system.}

Previous studies suggested that users' SAT is a predictive factor for the adoption of new information technology. According to expectation-confirmation model (ECM; [16]), users' perception of usefulness and confirmation (ie, whether the experience of information technologies meets their expectation) influences their SAT with the system, and the level of SAT predicts their continued intention to use the system. Ho's [17] study on electronic learning platforms found that users' SAT with the technology also affected their ATT toward the system. Given these findings from previous relevant studies, we hypothesized that trainees' SAT with the VR-assisted MR training system would influence both their ATT toward and intention to use the system.

\section{H6: Users'SAT with the system predicts their positive} ATT. 


\section{H7: Users'SAT with the system predicts their BIU.}

Figure 1 shows all the proposed hypotheses and the research model for this study.

To better understand how each factor interacts with others to affect learners' intention to use the VR-assisted MR training system and to provide more detailed implications for future researchers and practitioners, we asked the following research question to gauge the indirect effects among the constructs in this study.

RQ: Are there any indirect effects among the constructs in the proposed model?

Figure 1. The proposed theoretical research model includes perceived ease-of-use (PEOU), perceived enjoyment (PE), attitude (ATT), satisfaction (SAT), and behavioral intention to use the system (BIU). H: hypothesis.

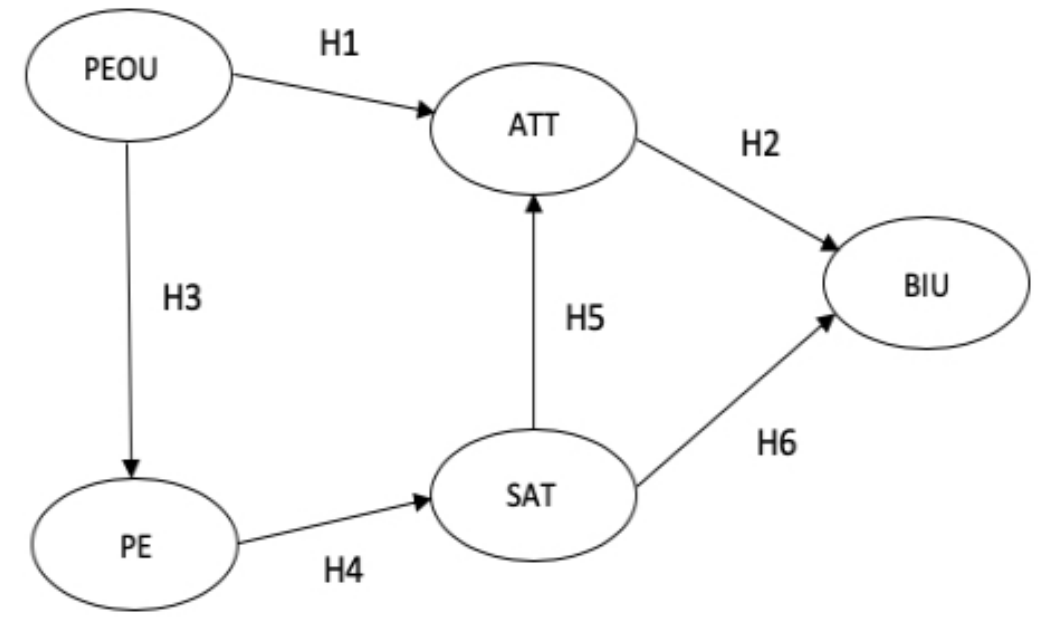

\section{Methods}

\section{System Design}

Shepard and Metzler [18] developed a paper-based MR test. Two 3D objects having the same geometric form but in different orientations were created on a 2D sheet. Trainees were typically asked to identify whether these 2 objects are the same. Developed from Shepard and Metzler's MR tasks, this study adopted 12 stereo and interactive MR tasks (2 for the purpose of practice and 10 for formal training) for our VR-assisted interactive MR training system. OpenGL (Khronos Group) [19], a computer graphic software, was used to create the 3D objects (see Figure 2 for the visual demonstration), and Quad-Buffer
Stereo [20] was used in OpenGL to create 120 frames per second for stereovision. For the hardware, RealID shutter glasses (ie, 3D glasses) were used by the participants (Figure 3). The mechanism of stereovision relies on visual persistence and the cross-display of 120 images between 2 eyes. For the interactive experience, Unity engine [21] was applied, so users could virtually rotate the MR subjects via a 6-degree-of-freedom (dof) controller (ie, joystick; Figure 4). In our study, trainees were asked to observe and rotate an MR object and drag it to superimpose a replicate on the other side of the screen that has the same geometric form but a different orientation. Once the 2 MR objects perfectly matched, the specific single MR task was accomplished.

Figure 2. The stereoscopic interactive mental rotation tasks created by the research team.

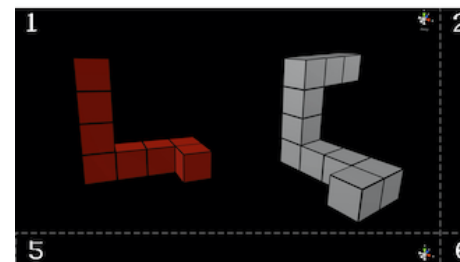

5

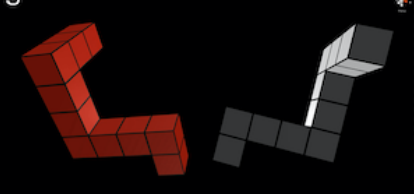

9

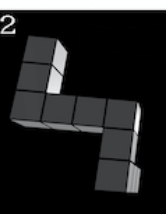

6
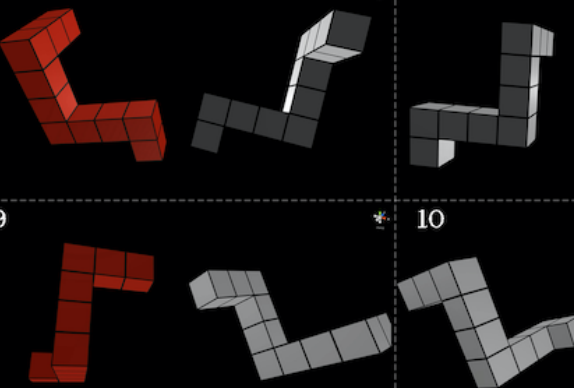

10

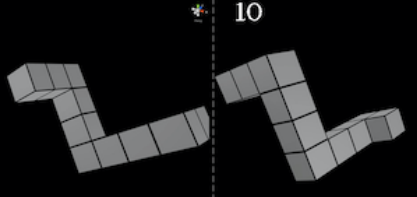

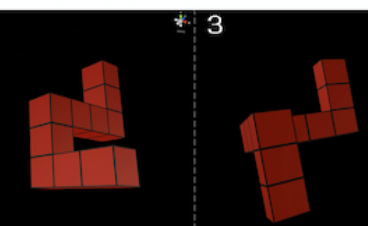

* 7

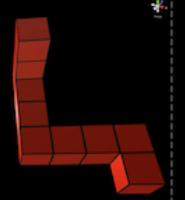

* 11

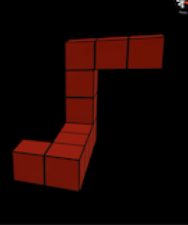

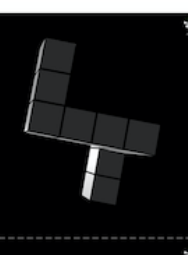

4

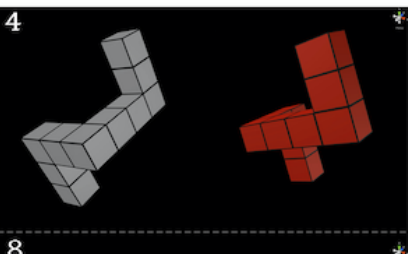

8
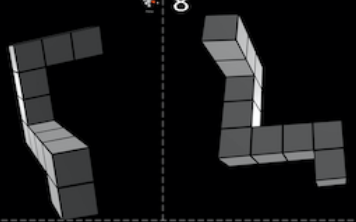

* 12

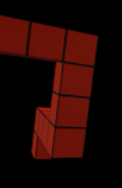

1

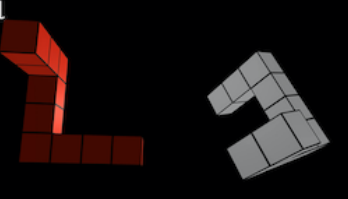

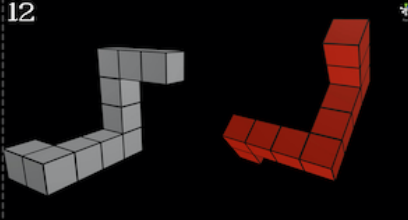


Figure 3. 3D glasses were used to facilitate the interactive virtual reality experience for mental rotation tasks (written, informed consent was obtained from the individual for publication of the image).

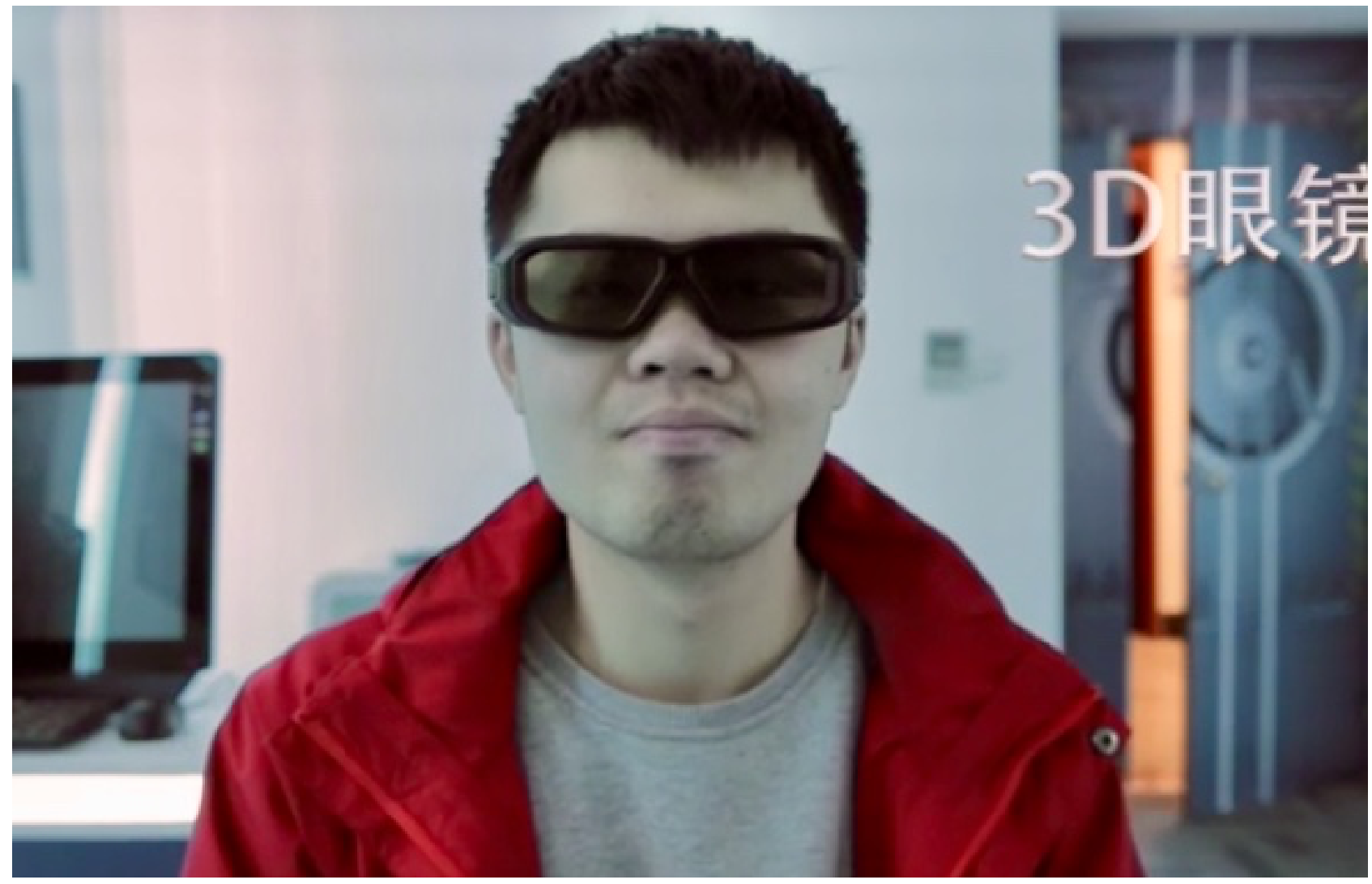

Figure 4. Joystick controller was used to facilitate the interactive virtual reality experience for mental rotation tasks.

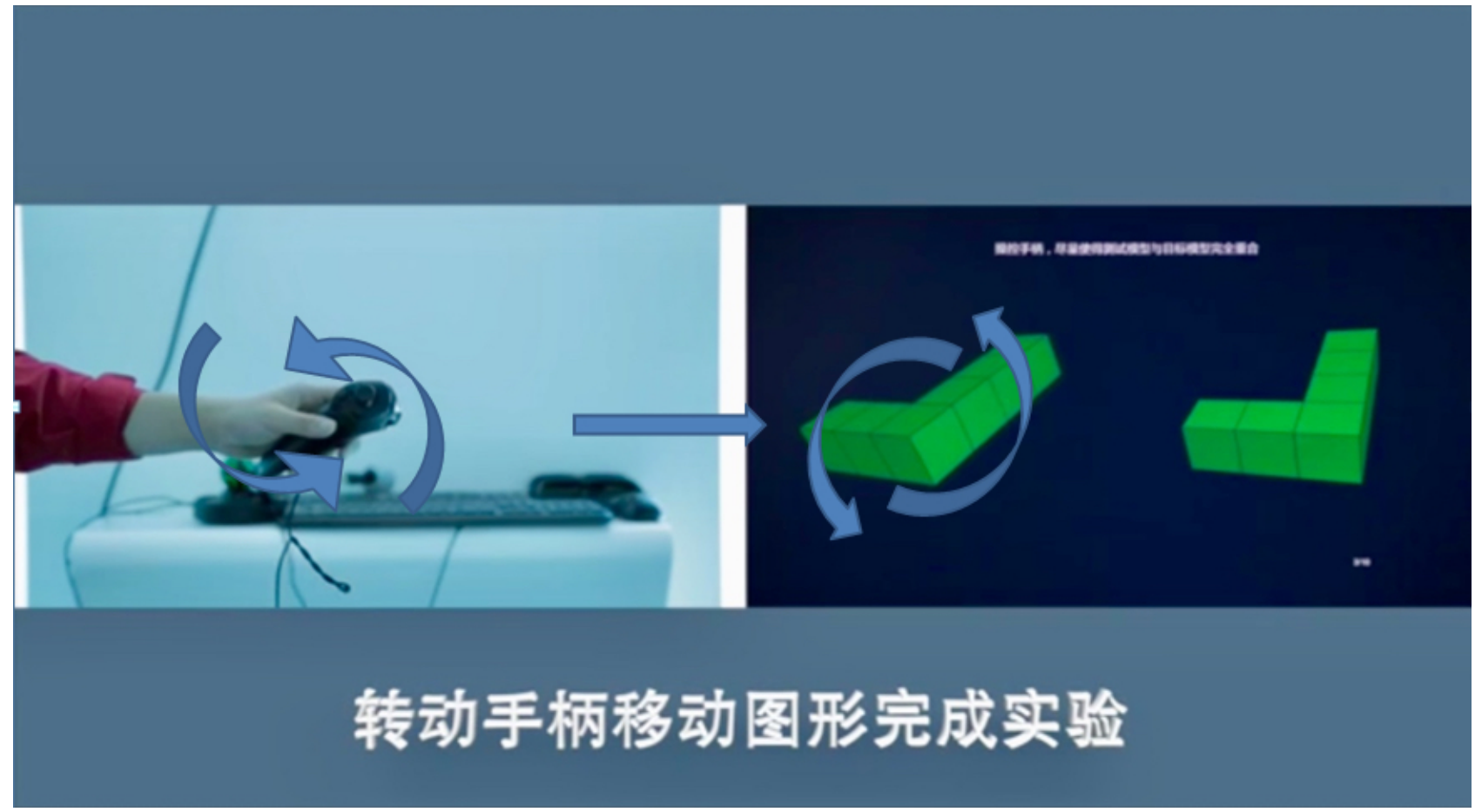

\section{Participants and Procedure}

This study used partial least squares structural equation modeling (PLS-SEM) for data analysis. PLS-SEM is one of the most used analytical technique by management information system and marketing researchers, and studies applying PLS-SEM have been published in journals such as MIS
Quarterly [22]. PLS-SEM suggests a 10-time rule for the sample size. The sample size must be 10 times greater than (1) the maximum number of paths a latent variable has and (2) the greatest indicators (items) a latent variable has in the model [23]. This study used a data subset of 55 participants from an earlier developed experimental study [24], which surpassed the 
2 threshold requirements. The students in this study were all recruited from the same large research university in Shanghai, China, in early 2018. Each of them received 10 RMB (about US \$1.5) to compensate their time. Their ages ranged from 18 to 26 years (mean 20.29, SD 1.85; median 20.00), with a control of approximate numbers of male $(n=29)$ and female $(n=26)$ participants. They came from diverse majors, including journalism, social science, psychology, Chinese, German, museum studies, mathematics, science, physics, microelectronics, electrical engineering, medicine, medical, chemistry, and electronical information science and technology. For the conditions analyzed in this study, the participants were first asked to watch an instruction video to understand the basic concept of MR and how to use the VR-assisted training equipment. Afterward, they were asked to use the VR equipment (ie, the stereoscopic display and 3D glasses and joystick controller) to perform $2 \mathrm{MR}$ tasks for practice and $10 \mathrm{MR}$ tasks for formal training, which were created by our research team, followed by a Web-based questionnaire. Owing to the nature of a data subset from a previous experimental study applying a reverse group design, nearly half of the participants in this study had experienced another condition-using a 3-dof computer mouse as the controller before their repeated practice using a 6-dof joystick controller. To prevent potential order effects, we added control variables reflecting the influences caused by the differences between the 2 groups to our analyzed PLS-SEM model. None of the control variable's effect was statistically significant, which indicated a similarity between groups.

\section{Measurement}

The measurement for the individual constructs were developed from previous theories and research in information systems and technology, some of which were introduced in the literature review (Table 1). Seven-point Likert scales were applied to PEOU, ATT, PE, and BIU. Semantic measures (7-point scales) were used for the constructs of SAT.

Table 1. Measurement scales.

\begin{tabular}{|c|c|c|}
\hline Construct & Item & Cronbach alpha \\
\hline $\begin{array}{l}\text { Perceived ease of use } \\
{[25]}\end{array}$ & $\begin{array}{l}\text { 1. My interaction with this } \mathrm{MR}^{\mathrm{a}} \text { system was clear and understandable. } \\
\text { 2. Interacting with this MR system did not require a lot of my effort. } \\
\text { 3. I found this MR system difficult to use (reversed; withdrawn because of a low factor loading). } \\
\text { 4. I found it easy to get this MR system to do what I wanted it to do. }\end{array}$ & .769 \\
\hline Attitude [26] & $\begin{array}{l}\text { 1. Using this MR system is a good idea. } \\
\text { 2. Using this MR system is a wise idea. } \\
\text { 3. I dislike the idea of using this MR system (reversed; withdrawn because of a low factor loading). } \\
\text { 4. Using this MR system is pleasant. }\end{array}$ & .935 \\
\hline $\begin{array}{l}\text { Perceived enjoyment } \\
{[13]}\end{array}$ & $\begin{array}{l}\text { 1. I found using this MR system to be enjoyable. } \\
\text { 2. The actual process of using this MR system was pleasant. } \\
\text { 3. I had fun using this MR system. }\end{array}$ & .959 \\
\hline Satisfaction [16] & $\begin{array}{l}\text { How did you feel about your overall experience of this MR system? (sematic measures): (1) Very dissat- } \\
\text { isfied }<-->\text { Very satisfied, (2) Very displeased }<-->\text { Very pleased, (3) Very frustrated }<-->\text { Very con- } \\
\text { tented, and (4) Absolutely terrible }<-->\text { Absolutely delighted }\end{array}$ & .862 \\
\hline $\begin{array}{l}\text { Behavioral intention of } \\
\text { use [25] }\end{array}$ & $\begin{array}{l}\text { 1. Assuming I had access to this MR system, I intend to use it. } \\
\text { 2. Given that I had access to this MR system, I predict that I would use it. }\end{array}$ & .948 \\
\hline
\end{tabular}

${ }^{\mathrm{a}} \mathrm{MR}$ : mental rotation.

\section{Results}

This study used IBM SPSS and SmartPLS 3 to analyze data. In SmartPLS 3, the outer model represents the measurement model, whereas the inner model is the same as the "structural model" in other structural equation modeling (SEM) software. Before the SEM analysis, the data were examined for outliers and univariate normality distributions. One case was deleted because of its extreme $\mathrm{z}$-score for a measured item. Afterward, the researchers examined the validity and reliability for the outer model in SmartPLS 3. As can be seen in the measurement, all the latent variables were considered internally consistent according to Nunnally and Bernstein's [27] rule of 0.7 for the Cronbach alpha, as they ranged from 0.769 to 0.959 . The convergent validity was met based on 3 criteria: (1) The indicators for individual constructs surpassed the threshold value of $0.7,(2)$ the composite reliability values were greater than 0.6 , and (3) each construct had a coefficient of average variance extracted (AVE) no less than 0.6 ([28,29]; see Table 2 for more details on the convergent validity). 
Table 2. Convergent validity.

\begin{tabular}{|c|c|c|c|c|c|}
\hline Construct & Item & Standardized loading & Composite reliability & $\mathrm{AVE}^{\mathrm{a}}$ & $\sqrt{ } \mathrm{AVE}$ \\
\hline \multirow[t]{3}{*}{$\mathrm{PEOU}^{\mathrm{b}}$} & PEOU1 & 0.837 & $-^{c}$ & - & - \\
\hline & PEOU2 & 0.871 & - & - & - \\
\hline & PEOU4 & 0.772 & 0.867 & 0.685 & 0.828 \\
\hline \multirow[t]{3}{*}{$\mathrm{ATT}^{\mathrm{d}}$} & ATT1 & 0.948 & - & - & - \\
\hline & ATT2 & 0.955 & - & - & - \\
\hline & ATT4 & 0.920 & 0.959 & 0.886 & 0.941 \\
\hline \multirow[t]{3}{*}{$\mathrm{PE}^{\mathrm{e}}$} & PE1 & 0.971 & - & - & - \\
\hline & PE2 & 0.970 & - & - & - \\
\hline & PE3 & 0.942 & 0.973 & 0.924 & 0.961 \\
\hline \multirow[t]{4}{*}{ SAT $^{\mathrm{f}}$} & SAT1 & 0.793 & - & - & - \\
\hline & SAT2 & 0.837 & - & - & - \\
\hline & SAT3 & 0.875 & - & - & - \\
\hline & SAT4 & 0.853 & 0.905 & 0.706 & 0.840 \\
\hline \multirow[t]{2}{*}{$\mathrm{BIU}^{\mathrm{g}}$ the system } & BIU1 & 0.975 & - & - & - \\
\hline & BIU2 & 0.975 & 0.975 & 0.951 & 0.975 \\
\hline
\end{tabular}

${ }^{a}$ AVE: average variance extracted.

${ }^{b}$ PEOU: perceived ease of use.

${ }^{\mathrm{c}}$ Not applicable.

d ATT: attitude.

${ }^{\mathrm{e}} \mathrm{PE}$ : perceived enjoyment.

${ }^{\mathrm{f}} \mathrm{SAT}$ : satisfaction.

${ }^{\mathrm{B}} \mathrm{BIU}$ : behavioral intention to use.

For the discriminant validity, the squared root of the AVE value for each construct was compared with the correlations between the construct and other latent variables. The results suggested that the coefficients of $\sqrt{ }$ AVE were all greater than other

correlations' Pearson r, which suggests a good discriminant validity for the outer model ([28]; see Table 3). The resulting variance inflation factors also suggested that no significant colinear relationship was identified.

Table 3. Correlation coefficients for discriminant validity.

\begin{tabular}{llcccc}
\hline Construct & PEOU $^{\mathrm{a}}$ & $\mathrm{ATT}^{\mathrm{b}}$ & $\mathrm{PE}^{\mathrm{c}}$ & $\mathrm{SAT}^{\mathrm{d}}$ & BIU $^{\mathrm{e}}$ \\
\hline PEOU & 0.828 & $-\mathrm{f}^{\mathrm{f}}$ & - & - & - \\
ATT & 0.521 & 0.941 & 0.961 & - & - \\
PE & 0.440 & 0.808 & 0.618 & 0.840 & - \\
SAT & 0.214 & 0.609 & 0.549 & 0.603 & 0.975 \\
BIU & 0.218 & 0.634 & & \\
\hline
\end{tabular}

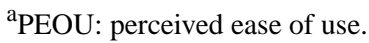

${ }^{\mathrm{b}}$ ATT: attitude.

${ }^{\mathrm{c}} \mathrm{PE}$ : perceived enjoyment.

${ }^{\mathrm{d}}$ SAT: satisfaction.

${ }^{\mathrm{e}} \mathrm{BIU}$ : behavioral intention to use.

${ }^{\mathrm{f}}$ Not applicable.

Given that the coefficient of standardized root mean squared residual, an index of model fit in SmartPLS 3, was less than .08 (.076 for the structural model and .079 for the estimated model), the data fit the model well [30]. Afterward, the inner model was created applying SmartPLS 3's PLS algorithm. All the path coefficients can be seen in Figure 5. To test their level of statistical significance, a bootstrapping algorithm was calculated 5000 times in the software, as suggested by Hair et al [31]. The 
results showed that 4 out of 7 path coefficients were statistically significant at a $P$ level of .05 . One path was marginally significant at a $P$ value of $.10(P=.07)$, and the other 2 paths were close to marginally significant $(P=.11$ and .12 ; see Table
4). The entire model explained $47.7 \%$ of the variance of BIU (including and excluding the control variables for groups for BIU: $48.6 \%$ and $47.7 \%$, respectively), which is considered moderately explanatory [32].

Figure 5. The partial least squares structural equation modeling structural model for the acceptance of our virtual reality-assisted mental rotation training system. ATT: attitude; BIU: behavioral intention to use; PE: perceived enjoyment; PEOU: perceived ease of use; SAT: satisfaction.

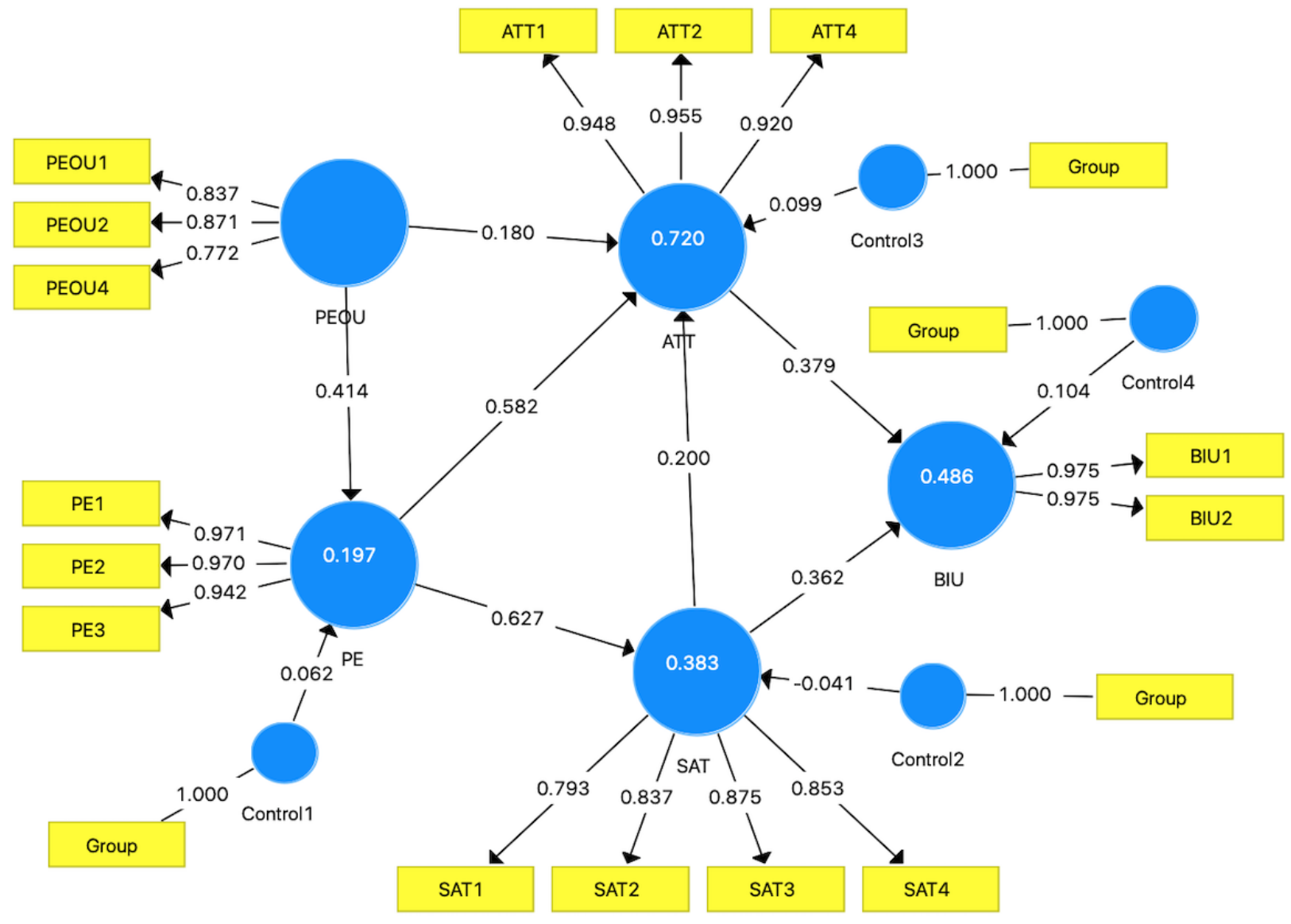

Table 4. Coefficients for the bootstrapping results.

\begin{tabular}{|c|c|c|c|c|c|}
\hline Path & Original beta $(\mathrm{O})$ & Sampling beta & SD & $\mathrm{T}(\mathrm{O} / \mathrm{SD})$ & $P$ values \\
\hline $\mathrm{ATT}^{\mathrm{a}}->\mathrm{BIU}^{\mathrm{b}}$ & .379 & .378 & 0.187 & 2.028 & $<.05$ \\
\hline $\mathrm{PE}^{\mathrm{c}} \rightarrow \mathrm{SAT}^{\mathrm{d}}$ & .627 & .634 & 0.085 & 7.398 & $<.001$ \\
\hline PE->ATT & .582 & .563 & 0.141 & 4.136 & $<.001$ \\
\hline PEOU $^{\mathrm{e}} \rightarrow$ ATT & .180 & .185 & 0.112 & 1.614 & .11 \\
\hline PEOU->PE & .414 & .442 & 0.141 & 2.943 & $<.01$ \\
\hline SAT $->$ ATT & .200 & .213 & 0.128 & 1.567 & .12 \\
\hline SAT $\rightarrow$ BIU & .362 & .359 & 0.199 & 1.819 & $<.10$ \\
\hline
\end{tabular}

${ }^{\mathrm{a}}$ ATT: attitude.

${ }^{b}$ BIU: behavioral intention to use.

${ }^{\mathrm{c}}$ PE: perceived enjoyment.

${ }^{\mathrm{d}}$ SAT: satisfaction.

${ }^{\mathrm{e}} \mathrm{PEOU}$ : perceived ease of use.

To better understand how each construct interacted with other variables in the model, indirect effects (mediations) were also examined based on a 5000-time bootstrapping sample. As can be seen from Table 5, all indirect effects (including specific paths) for endogenous variables were exported and compared. Regarding the indirect effect on the variable of SAT, PE 
significantly mediated the influence of PEOU on SAT (beta=.259). For the construct of ATT, the indirect effect via the path PEOU $\rightarrow$ PE->ATT significantly mediated the effect of PEOU on ATT (beta=.241). For BIU, PE and PEOU's effects were both significantly mediated by other variables (beta $=.495$ and beta=.273). Specifically, PE's effect on BIU consisted of the marginally significant paths of PE->ATT $->$ BIU (beta=.220) and PE->SAT->BIU (beta=.227).

Table 5. Mediation effects (indirect effects).

\begin{tabular}{|c|c|c|c|c|c|c|c|}
\hline \multirow[t]{2}{*}{ Construct } & \multicolumn{2}{|c|}{ Direct effects } & \multicolumn{2}{|c|}{ Indirect effects } & \multirow[t]{2}{*}{ Specific paths } & \multicolumn{2}{|c|}{ Specific effects } \\
\hline & Beta value & $P$ value & Beta value & $P$ value & & Beta value & $P$ value \\
\hline \multicolumn{8}{|l|}{ SAT $^{\mathbf{a}}$} \\
\hline $\mathrm{PEOU}^{\mathrm{b}} \rightarrow \mathrm{SAT}$ & $-^{c}$ & - & $.259^{\mathrm{d}}$ & .005 & PEOU->PE->SAT & $.259^{\mathrm{d}}$ & - \\
\hline \multicolumn{8}{|l|}{$\mathbf{A T T}^{\mathrm{e}}$} \\
\hline$P E^{f} \rightarrow A_{T T}$ & $.582^{\mathrm{g}}$ & $<.001$ & .126 & .19 & PE $->$ SAT $->$ ATT & .126 & - \\
\hline PEOU->ATT & .180 & .11 & $.293^{\mathrm{h}}$ & .01 & PEOU $->P E->A T T$ & $.241^{\mathrm{h}}$ & - \\
\hline - & - & - & - & - & PEOU $->$ PE $->$ SAT $->$ ATT & .052 & - \\
\hline \multicolumn{8}{|l|}{ BIU $^{\mathrm{i}}$} \\
\hline $\mathrm{PE}->\mathrm{BIU}$ & - & - & $.495^{\mathrm{g}}$ & $<.001$ & PE->ATT $->$ BIU & $.220^{\mathrm{j}}$ & .05 \\
\hline - & - & - & - & - & PE->SAT->BIU & $.227^{\mathrm{j}}$ & .08 \\
\hline- & - & - & - & - & PE $->$ SAT $->$ ATT $->$ BIU & .048 & - \\
\hline PEOU->BIU & - & - & $.273^{\mathrm{d}}$ & .002 & PEOU $->A T T->B I U$ & .068 & - \\
\hline- & - & - & - & - & PEOU->PE->ATT->BIU & .091 & - \\
\hline- & - & - & - & - & PEOU->PE->SAT $->$ BIU & .094 & - \\
\hline - & - & - & - & - & PEOU $->$ PE $->$ SAT $->$ ATT $->$ BIU & .020 & - \\
\hline SAT $->$ BIU & $.362^{\mathrm{j}}$ & .07 & .076 & .31 & SAT $->$ ATT $->$ BIU & .076 & - \\
\hline
\end{tabular}

${ }^{\text {a}} \mathrm{SAT}$ : satisfaction.

${ }^{b}$ PEOU: perceived ease of use.

${ }^{\mathrm{c}}$ Not applicable.

${ }^{\mathrm{d}} P<.01$.

${ }^{\mathrm{e}} \mathrm{ATT}$ : attitude.

${ }^{\mathrm{f}} \mathrm{PE}$ : perceived enjoyment.

${ }^{\mathrm{g}} P<.001$.

${ }^{\mathrm{h}} P<.05$.

${ }^{\mathrm{i}} \mathrm{BIU}$ : behavioral intention to use.

$\mathrm{j}_{P<.10 \text {. }}$

\section{Discussion}

\section{Key Findings and Theoretical Discussion}

This study created a theoretical model to examine how determining factors from relevant theories of technology acceptance can be used to explain the acceptance of a novel VR-assisted MR training system created by our research team. The results suggested that ATT affected BIU (beta=.379; H2). This finding is consistent with the TAM [1]. We also found that PEOU's effect on ATT was mediated by PE (beta=.241). The indirect effect of PEOU on BIU was mediated by other variables in the model (beta=.273). PEOU has been a crucial factor affecting users' acceptance of information systems. In our study, it is likely that applying VR technology to both the hardware and software of the MR training system was relatively new and

novel to the trainees. As most users were new to the VR system, they were not that familiar with its usage compared with other information technology they use in their everyday lives. Therefore, PEOU served as the predictive factor for their ATT toward and intention to use the VR-assisted MR training system. Whenever trainees perceived the use of our MR training system as easier, they had a better ATT toward the system and a higher intention to use it. By examining the key constructs' direct and indirect effects, our study extended the current TAM theory from the context of information technology and systems to VR educational technology and further expanded the findings from recent applications of TAM in other VR-assisted systems (eg, $[11,12])$.

In addition, this study replicated the finding of the study conducted by Davis et al [13] that PE was affected by PEOU 
(beta=.414; H3). That is, trainees who regarded the MR training system as more effortless to use would perceive a higher level of enjoyment. In contrast, whenever users felt that using the system was challenging, their PE decreased. Furthermore, our study suggested that PE not only served as a variable that is influenced by PEOU but also served as the mediator between PEOU and other constructs in the model. Specifically, PE mediated the effect between PEOU and SAT (beta=.259) and partially mediated the effect of PEOU on ATT (beta=.241). Other than these findings, our study also verified that PE affected ATT (beta=.582; H4) and SAT (beta=.627; H5), as we had hypothesized. Those trainees who perceived a higher level of enjoyment had a more positive ATT toward and SAT with the system.

Extending the finding from the study by Davis et al [13] that PE played the predictive role in BIU and actual use, this study showed that PE affected BIU, mediated by ATT and SAT, specifically with the paths of PE->SAT $->$ BIU (beta=.227) and PE->ATT $\rightarrow$ BIU (beta=.220). Users' PE first affected their SAT with and ATT toward the system, which later influenced their intention to use the system. Our study, thus, extended Davies' suggested psychological relationship between joyful perception and behavioral intention by adding 2 attitudinal factors, ATT and SAT, between them. In other words, a chain relationship, joyful perception->attitudinal factors->behavioral intention, was created. This study suggested the importance of ATT and SAT as the mediators when considering PE's influence on BIU.

Finally, aligning with the ECM [16], we found that trainees' SAT with the MR system directly predicted their intention to use it (beta=.362; H7). Whenever the VR-assisted training system satisfied the users, they were likely to adopt it for learning. SAT, thus, also played a mediating role between PE and BIU (beta=.227), as discussed in the previous paragraph.

\section{Practical Implications}

On the basis of the findings of this established model, we also provide practical implications for MR trainers, technology developers, and education professionals. The empirical evidence of this study suggested that trainees' intention to use the novel VR-assisted interactive MR training system was predicted by their PEOU and PE (indirectly via ATT or SAT). Given that the use of an MR training system enhances trainees' MR ability [2], suggestions for technology developers and educators based on the previous 2 exogenous factors are discussed and aimed at helping relevant professionals better apply VR-assisted technologies and systems for education.

The predictive role of PEOU suggests that a user-friendly design is necessary for a VR-assisted MR training system. This requirement is understandable, as VR technology is relatively new and novel to consumers when compared with other information technology and systems on the market. VR technology developers are encouraged to keep improving system's ease-of-use function, specifically with its hardware (eg, stereoscopic glasses and display and interactive controller), as well as the interactive design between the users and MR objects via the controller in the virtual environment. Future systems might want to consider eliminating tools and use of a physical controller and instead develop a motion sensor to completely rely on the trainees' gestures or body movements to interact with the virtual content. These suggested approaches could effectively increase trainees' PEOU, which would eventually lead to their better intention to use the training system.

$\mathrm{PE}$, as we had predicted, served as the predictive factor for the use of the MR training system. We suggest that technology developers might further develop a system that complements the VR head-mounted display (HMD) that completely separates the real and virtual environments. An HMD could further create a better spatial presence by allowing users to actively switch their field-of-view rather than passively observe the content [33]. Previous studies found that whenever spatial presence increased, observers' enjoyment amped up accordingly [34,35], as cited in the paper by Ravaja et al [36]. For the tasks of MR training, game scenarios such as stereoscopic 3D interactive Tetris could be created, which would likely be more playful for users. It is clearly supported by previous studies on digital learning (eg, $[37,38])$ that users in a game-playing situation perceived increased enjoyment.

\section{Limitations and Future Research}

Similar to other studies, this research has its limitations and needs future research to further gauge unanswered questions. First, although all the causal hypotheses were based on established theories and previous studies, the nature of the data for our proposed theoretical model is cross-sectional. Future studies capable of conducting experiments are encouraged to investigate the relationships between the constructs explored in our model. Furthermore, this study explored the acceptance level of VR's educational application in the context of MR. Other educational and training activities, which might apply VR technology in slightly different ways, are also worth further exploration. These extended studies would help researchers and practitioners have a holistic understanding regarding how VR technology can be accepted for educational purposes. Finally, although our proposed theoretical model explained nearly half $(47.7 \%)$ of the variance of BIU, other VR-specific factors on trainees' use of the novel VR-assisted interactive MR training system, such as perceived simulation and presence, need to be developed and incorporated into the model to better comprehend the remaining unanswered variance for adoption intention.

\section{Acknowledgments}

This work was supported by the School of Journalism at Fudan University and Xijia Great Education Technology Co, Ltd.

\section{Conflicts of Interest}

None declared. 


\section{References}

1. Davis FD, Bagozzi RP, Warshaw PR. User acceptance of computer technology: a comparison of two theoretical models. Manage Sci 1989;35(8):982-1003. [doi: 10.1287/mnsc.35.8.982]

2. Yeh SC, Wang JL, Wang CY, Lin PH, Chen GD, Rizzo A. Motion controllers for learners to manipulate and interact with 3D objects for mental rotation training. Br J Educ Technol 2013;45(4):666-675. [doi: 10.1111/bjet.12059]

3. Merchant Z, Goetz ET, Cifuentes L, Keeney-Kennicutt W, Davis TJ. Effectiveness of virtual reality-based instruction on students' learning outcomes in K-12 and higher education: A meta-analysis. Comput Educ 2014;70:29-40. [doi: 10.1016/j.compedu.2013.07.033]

4. Linn MC, Petersen AC. Emergence and characterization of sex differences in spatial ability: a meta-analysis. Child Dev 1985 Dec;56(6):1479-1498. [doi: 10.2307/1130467] [Medline: 4075870]

5. Vandenberg SG, Kuse AR. Mental rotations, a group test of three-dimensional spatial visualization. Percept Mot Skills 1978 Oct;47(2):599-604. [doi: 10.2466/pms.1978.47.2.599] [Medline: 724398]

6. Guillot A, Champely S, Batier C, Thiriet P, Collet C. Relationship between spatial abilities, mental rotation and functional anatomy learning. Adv Health Sci Educ Theory Pract 2007 Nov;12(4):491-507. [doi: 10.1007/s10459-006-9021-7] [Medline: $16847728]$

7. Hoyek N, Collet C, Rastello O, Fargier P, Thiriet P, Guillot A. Enhancement of mental rotation abilities and its effect on anatomy learning. Teach Learn Med 2009 Jul;21(3):201-206. [doi: 10.1080/10401330903014178] [Medline: 20183339]

8. Fishbein M, Ajzen I. Belief, Attitude, Intention and Behavior: An Introduction to Theory and Research. Boston, Massachusetts, United States: Addison-Wesley; 1977.

9. Liu IF, Chen MC, Sun YS, Wible D, Kuo CH. Extending the TAM model to explore the factors that affect Intention to Use an Online Learning Community. Comput Educ 2010;54(2):600-610. [doi: 10.1016/J.COMPEDU.2009.09.009]

10. Ngai EW, Poon JK, Chan YH. Empirical examination of the adoption of WebCT using TAM. Comput Educ 2007;48(2):250-267. [doi: 10.1016/J.COMPEDU.2004.11.007]

11. Huang H, Liaw S, Lai C. Exploring learner acceptance of the use of virtual reality in medical education: a case study of desktop and projection-based display systems. Interact Learn Environ 2013;24(1):1-17 [FREE Full text] [doi: $\underline{10.1080 / 10494820.2013 .817436]}$

12. Rasimah CM, Ahmad A, Zaman HB. Evaluation of user acceptance of mixed reality technology. Aust J Educ Technol 2011;27(8):1369-1387 [FREE Full text] [doi: 10.14742/ajet.899]

13. Davis FD, Bagozzi RP, Warshaw PR. Extrinsic and intrinsic motivation to use computers in the workplace. J Appl Soc Psychol 2006;22(14):1111-1132. [doi: 10.1111/j.1559-1816.1992.tb00945.x]

14. Moon JW, Kim YG. Extending the TAM for a World-Wide-Web context. Inf Manag 2001;38(4):217-230. [doi: $\underline{10.1016 / \mathrm{S} 0378-7206(00) 00061-6]}$

15. Martocchio JJ, Webster J. Effects of feedback and cognitive playfulness on performance in microcomputer software training. Pers Psychol 1992;45(3):553-578. [doi: 10.1111/j.1744-6570.1992.tb00860.x]

16. Bhattacherjee A. Understanding information systems continuance: an expectation-confirmation model. Manag Inf Syst $Q$ 2001;25(3):351-370. [doi: 10.2307/3250921]

17. Ho CH. Continuance intention of e-learning platform: toward and integrated model. Int J Electron Bus Manag 2010;8(3):206-215 [FREE Full text]

18. Shepard RN, Metzler J. Mental rotation of three-dimensional objects. Science 1971 Feb 19;171(3972):701-703. [doi: 10.1126/science.171.3972.701] [Medline: 5540314]

19. OpenGL. URL: https://www.opengl.org/ [accessed 2019-12-18]

20. Theoretical and Computational Biophysics Group. Quad-Buffered Stereo. URL: https://www.ks.uiuc.edu/Research/vmd/ current/ug/node102.html [accessed 2019-12-18]

21. Unity Real-Time Development Platform. URL: https://unity.com [accessed 2019-12-18]

22. Ringle CM, Sarstedt M, Straub DW. Editor's comments: a critical look at the use of PLS-SEM in 'MIS Quarterly'. Manag Inf Syst Q 2012;36(1):iii-xiv. [doi: 10.2307/41410402]

23. Barclay D, Higgins C, Thompson R. The partial least squares approach (PLS) to causal modeling, personal computer adoption and use as an illustration. Technol Stud 1995;2(2):285-309 [FREE Full text]

24. Chang C, Heo J, Yeh S, Han H, Li M. The Effects of Immersion and Interactivity on College Students' Acceptance of a Novel VR-Supported Educational Technology for Mental Rotation. IEEE Access 2018;6:66590-66599. [doi: 10.1109/ACCESS.2018.2878270]

25. Venkatesh V. Determinants of perceived ease of use: integrating control, intrinsic motivation, and emotion into the technology acceptance model. Inf Syst Res 2000;11(4):342-365. [doi: 10.1287/isre.11.4.342.11872]

26. Taylor S, Todd PA. Understanding information technology usage: a test of competing models. Inf Syst Res 1995;6(2):144-176. [doi: 10.1287/isre.6.2.144]

27. Nunnally JC, Bernstein IH. Psychometric Theory. New York: McGraw-Hill; 1967.

28. Fornell C, Larcker DF. Evaluating structural equation models with unobservable variables and measurement error. J Mark Res 1981;18(1):39-50. [doi: 10.1177/002224378101800104] 
29. Hair JF, Black B, Babin B, Anderson RE, Tatham RL. Multivariate Data Analysis. Sixth Edition. New Jersey: Pearson; 2006.

30. Hu L, Bentler PM. Cutoff criteria for fit indexes in covariance structure analysis: conventional criteria versus new alternatives. Struct Equ Model 1999;6(1):1-55. [doi: 10.1080/10705519909540118]

31. Hair J, Hult GT, Ringle CM, Sarstedt M. A Primer on Partial Least Squares Structural Equation Modeling (PLS-SEM). Thousand Oaks, CA: Sage; 2016.

32. Henseler J, Ringle CM, Sinkovics RR. The use of partial least squares path modeling in international marketing. In: Sinkovics R, Ghauri P, editors. New Challenges to International Marketing (Advances in International Marketing, Volume 20). Bingley: Emerald Group Publishing Limited; 2009:277-319.

33. van DBA. Observe or Participate: The Effect of Point-of-View on Presence and Enjoyment in 360 Degree Movies for Head Mounted Displays. In: Proceedings of The European Conference on Ambient Intelligence. 2015 Presented at: AmI'15;

November 11-13, 2015; Athens, Greece. [doi: 10.1007/978-3-319-26005-1]

34. Heeter C. Communication research on consumer VR. In: Biocca F, Levy MR, editors. Communication in the Age of Virtual Reality. Hillsdale, NJ, US: Lawrence Erlbaum Associates; 1995:191-218.

35. Lombard M, Reich R, Grabe M, Bracken C, Ditton T. Presence and television: the role of screen size. Human Comm Res 2000;26(1):75-98. [doi: 10.1111/j.1468-2958.2000.tb00750.x]

36. Ravaja N, Saari T, Turpeinen M, Laarni J, Salminen M, Kivikangas M. Spatial presence and emotions during video game playing: does it matter with whom you play? Presence 2006;15(4):381-392. [doi: 10.1162/pres.15.4.381]

37. Fu FL, Su RC, Yu SC. EGameFlow: a scale to measure learners' enjoyment of e-learning games. Comput Educ 2009;52(1):101-112. [doi: 10.1016/j.compedu.2008.07.004]

38. Hsiao HC. A Brief Review of Digital Games and Learning. In: Proceedings of the 2007 First IEEE International Workshop on Digital Game and Intelligent Toy Enhanced Learning. 2007 Presented at: DIGITEL'07; March 26-28, 2007; Jhongli City, Taiwan. [doi: 10.1109/DIGITEL.2007.3]

\author{
Abbreviations \\ ATT: attitude \\ AVE: average variance extracted \\ BIU: behavioral intention to use \\ dof: degree-of-freedom \\ ECM: expectation-confirmation model \\ HMD: head-mounted display \\ MR: mental rotation \\ PE: perceived enjoyment \\ PEOU: perceived ease of use \\ PLS-SEM: partial least squares structural equation modeling \\ PU: perceived usefulness \\ SAT: satisfaction \\ SEM: structural equation modeling \\ TAM: technology acceptance model \\ VR: virtual reality
}

Edited by G Eysenbach; submitted 02.05.19; peer-reviewed by S McRoy, S Gallagher; comments to author 31.05.19; revised version
received 27.09.19; accepted 29.11.19; published 17.01.20
Please cite as:
Chang CW, Yeh SC, Li M
The Adoption of a Virtual Reality-Assisted Training System for Mental Rotation: A Partial Least Squares Structural Equation Modeling
Approach
JMIR Serious Games 2020;8(1):e14548
URL: $\underline{\text { http://games.jmir.org/2020/1/e14548/ }}$
doi: $10.2196 / 14548$
PMID: $\underline{31804184}$

(C) Chen-Wei Chang, Shih-Ching Yeh, Mengtong Li. Originally published in JMIR Serious Games (http://games.jmir.org), 17.01.2020. This is an open-access article distributed under the terms of the Creative Commons Attribution License (https://creativecommons.org/licenses/by/4.0/), which permits unrestricted use, distribution, and reproduction in any medium, 
provided the original work, first published in JMIR Serious Games, is properly cited. The complete bibliographic information, a link to the original publication on http://games.jmir.org, as well as this copyright and license information must be included. 